\title{
REVIEW
}

\section{NEUROENDOCRINE NEOPLASMS IN ITALY}

\author{
L. Mangone 1, I. Bisceglia 1, C. Sacchettini ${ }^{2}$, P. Mancuso ${ }^{1}$, G. Carlinfante ${ }^{\text {, }}$ \\ P. Giorgi Rossi ${ }^{1}$, AIRTUM Working Group ${ }^{4}$
}

\author{
${ }^{1}$ Epidemiology Unit, Azienda Unità Sanitaria Locale-IRCCS di Reggio Emilia, Reggio Emilia, Italy \\ 2 Department of Medical Sciences, University of Turin, Turin, Italy \\ ${ }^{3}$ Pathology Unit, Azienda Unità Sanitaria Locale-IRCCS di Reggio Emilia, Reggio Emilia, Italy \\ ${ }^{4}$ Associazione Italiana Registri Tumori (AIRTUM), Italy
}

\section{CORRESPONDING AUTHOR:}

\author{
Lucia Mangone \\ Epidemiology Unit \\ AUSL-IRCCS di Reggio Emilia \\ via Amendola 2 \\ 42122 Reggio Emilia, Italy \\ E-mail: mangone.lucia@ausl.re.it \\ ORCID: 0000-0003-4850-2678
}

Doi: $10.48286 / a r o .2021 .14$

History

Received: Mar 25, 2021

Accepted: Apr 6, 2021

Published: Jun 1, 2021

\begin{abstract}
Neuroendocrine neoplasms (NENs) account for $0.5 \%$ of all neoplasms worldwide. The aim of the study was to describe the epidemiology of NENs in Italy and the association with a second neoplasm using the Italian Cancer Registries (AIRTUM) database. Thirty-eight cancer registries were involved in this study in the period 1976-2012. The standardized incidence rates and the relative 5-year survival are reported. Cases by site, sex, and age, and the second cancers associated with patients with NENs are described.
\end{abstract}

A total of 9,707 NENs were reported to the AIRTUM database: 5,318 males (54.8\%) and 4,389 females (45.2\%). Lung and small intestine were the most frequent sites in both sexes. The standardized incidence increased from 1 case per 100,000/year (1976) to 5.46 case per 100,000/year in 2010 (95\% $\mathrm{Cl}$ 4.90-6.06), with a significant difference between rates in males $(6.51,95 \% \mathrm{Cl} 5.61-7.51)$ and in females (4.60, $95 \mathrm{Cl}$ 3.91-5.37). Incidence increased gradually in both sexes up to age 40-45, after which it increased rapidly. The 5-year relative survival was $59.7 \%$ (53.9\% in males and $66.5 \%$ in females). NEN patients had a slight, not significant excess risk of having a second tumour: standardized incidence ratio 1.06 (95\% Cl 0.98-1.15). Of the 9,707 NENs studied, 2,033 (21\%) had a second neoplasm: among these, 29 were NENs, 1,360 were other previous tumours, and 644 were other following tumours (78 synchronous and 566 metachronous tumours).

Although traditionally thought to be rare, incidence has increased by nearly sevenfold since 1976 . Differences in registration accuracy and classification criteria challenge comparisons between areas and time. 


\section{KEY WORDS}

Neuroendocrine neoplasms; incidence; epidemiology; second tumours.

\section{IMPACT STATEMENT}

This work highlights how the incidence of neuroendocrine tumors, although rare, is increasing in Italy and the association with second tumors was also evaluated. It can be of support in the choices of clinicians for the management of patients.

NETs the expression of neuroendocrine markers but are different from a genetic, histological, and predictive point of view (11). The current 2019 WHO classification of digestive system NETs grades tumours as G1, G2, or G3 on the basis of proliferation activity as assessed by mitotic rate and KI67 proliferation index. They are morphologically distinct from NECs, whose subtypes are small cell NEC and large cell NEC (12). The 2020 WHO classification for neuroendocrine neoplasia of female genital tract is still largely based on the 2018 WHO version as other organs will be in the next classifications (13). NENs have in general been considered indolent tumours with low metastatic potential. However, some NEN subtypes are highly malignant and have a bad prognosis as they are resistant to therapy (1). Incidence is increasing but it is unclear whether this trend is due to an increased awareness among physicians, to improved diagnostic tools, or to an actual increase in NENs incidence (7).

The aim of this study was to describe the incidence and survival of NENs in Italy and a possible association with second neoplasm, using the AIRTUM (Italian Association of Cancer Registries) database.

\section{MATERIALS AND METHODS}

\section{Cancer registries and data source}

Thirty-eight Italian cancer registries (CR) participated in the study, sending their data to the AIRTUM database. Data include both tumour characteristics and patient information, and in 2019, covered approximately $70 \%$ of the total Italian population. The dataset contained more than $3,000,000$ neoplasms (all tumours) diagnosed between 1976 and 2015 but this study includes 9,707 cases of NENs diagnosed only in the years 1976-2010, because data for the subsequent period were not complete. The 


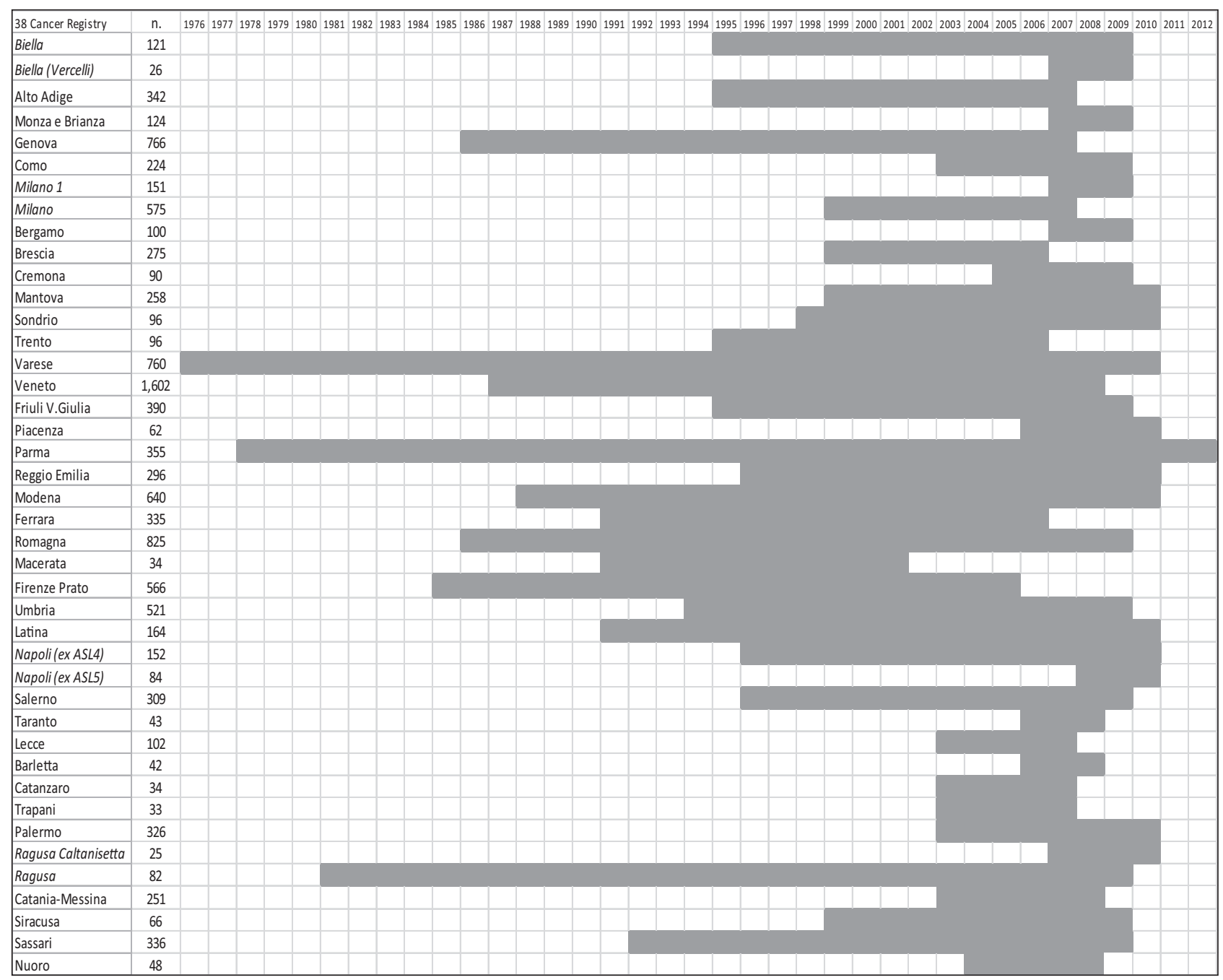

Figure 1. List of 38 cancer registries* participating in the study and number of cases per year. $(*$ in italics are the cancer registries that have merged in recent years).

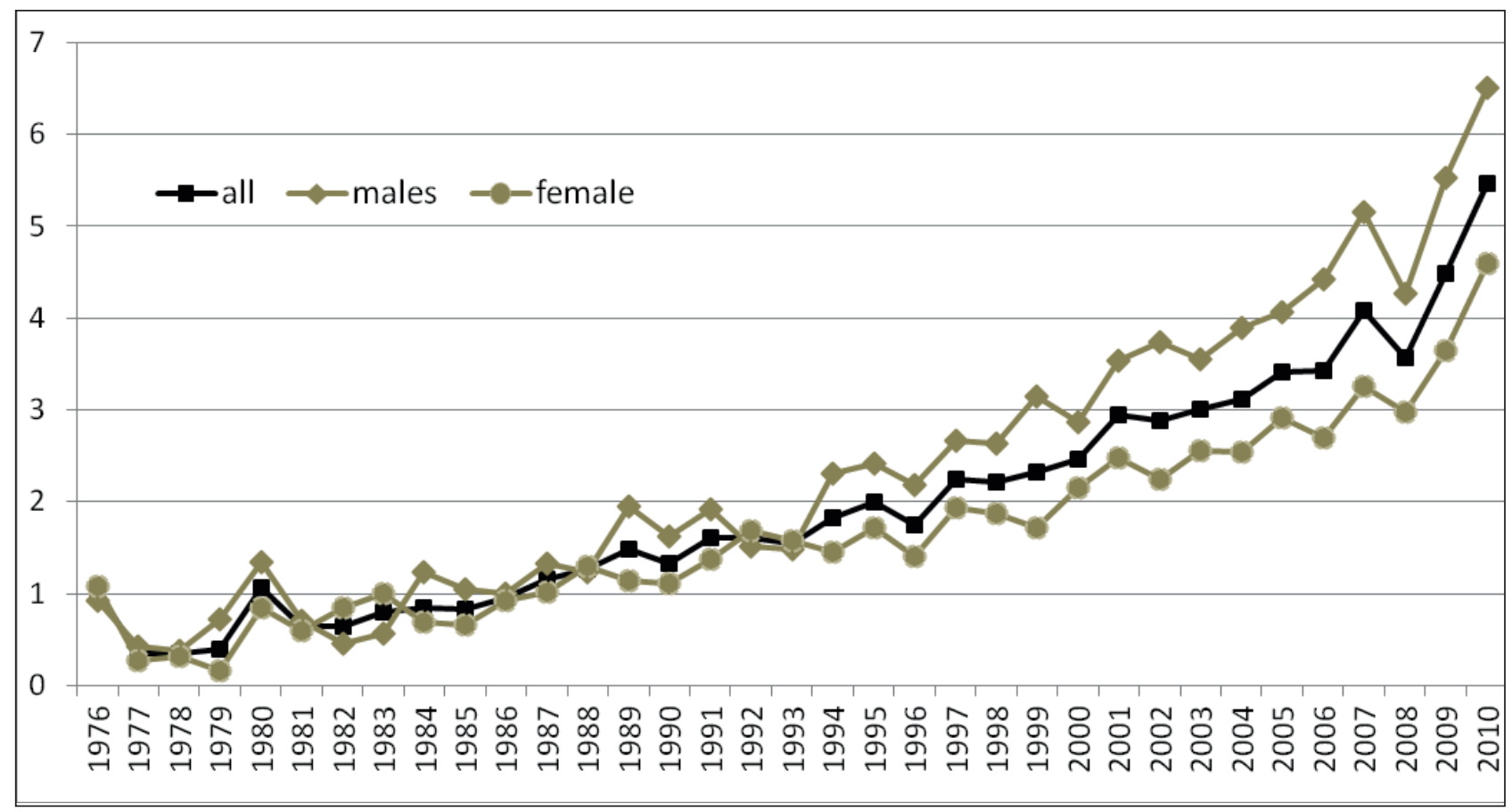

Figure 2. EU standardized incidence rates for 100,000 years/person. Years 1976-2010. 
cancer registries included throughout the study period varied; they are described in figure 1. ICD-O-3 histology codes were used to identify NENs, which includes (table 1): islet cell carcinoma, insulinoma, glucagonoma, gastrinoma, mixed islet-cell/exocrine adenocarcinoma, vipoma, somatostatinoma, enteroglucagonoma, carcinoid, enterochromaffin cell carcinoid, enterochromaffin-like cell tumours, goblet cell carcinoid, composite carcinoid, adenocarcinoid, neuroendocrine carcinoma, and atypical carcinoid. Small cell and large cell neuroendocrine carcinoma of the lung, pheomochromocytoma, paraganglioma were excluded, as already proposed by Yao in 2008 (3). WHO classification based on grading was not routinely available inn cancer registries during the period under study.

\section{Statistics}

We have reported cases by site and sex. The incidence rate per 100,000 population per year, standardized on the European population 2013, was calculated from 1976 to 2010 because 2011-2012 included data from only one CR. Age-specific rates were calculated over the whole period 1976-2012 per 1,000,000 to better distinguish between trends in males and females.

The 5-year relative survival, with relative $95 \% \mathrm{Cl}$, was calculated using the actuarial method (14).Second tumours were calculated by crossing the NENs with all the tumours in the database and evaluating the second tumours before or after a diagnosis of NENs. The latter were termed synchronous if they arose within two months of diagnosis or metachronous if they occurred 2 months after a diagnosis of NEN. Standardized incidence ratio for all cancer sites except non-melanoma skin cancers was computed using age groups of 10-year specific rates to compare the incidence of second cancers after the diagnosis of a NEN with the expected number of cancers in a similar population according to the age-specific incidence for all sites observed in Italy for the same period.

\section{RESULTS}

Between 1976 and 2012, a total of 9,707 NENs were reported to the AIRTUM database: 5,318 males (54.8\%) and 4,389 females (45.2\%). Lung (35.8\%), small intestine (16\%), and pancreas (10.2\%) were the most frequent sites in males, while lung (29.6\%), small intestine (12.8\%), and colon (12.1\%) were the most frequent sites in females (table II). Of the colon cancers, 302 cases were located in the appendix site (C18.1), mostly NOS (not otherwise specified) carcinoids.

The standardized incidence rate calculated on all the cases was equal to $1.97 / 100,000 /$ year but with a great variability by sex and by period. In fact, the trend of NENs in Italy has gradually increased since the 1980s, going from a rate of 1 case per 100,000 to over 5 cases per 100,000 in recent years (figure 2), more so for code 8246.3 (neuroendocrine carcinoma) than for 8240.3 (carcinoid). In 2010, the last available year, the rate was $5.46(95 \% \mathrm{Cl}$ 4.906.06), with a significant difference between males (SIR 6.51, 95\% CI 5.61-7.51) and females (SIR 4.60, 95\% Cl 3.91-5.37) (table III). Concerning age, the incidence increased gradually in both sexes up to age 40-45, after which it increased rapidly especially in males, where it reached 8 cases per 100,000; in females it reached 6 cases per 100,000, then decreased in both sexes from age 75 on (figure 3 ). The 5-year relative survival, referred to the period 1976-2010 with follow-up to 2015 , was $59.7 \%$ (95\% Cl 58.5-60.9): $53.9 \%$ in males and $66.5 \%$ in females. Of the 9,707 NENs studied, 2,033 (21\%) had a second neoplasm: of these, 29 were NENs, 1.360 other previous cancers, and 644 were other following tumour (78 synchronous and 566 metachronous tumours) (figure 4). Of the 78 synchronous cases, the majority were lung (15 cases), colon (11 cases), prostate, kidney, and thyroid (6 cases). Of the 566 metachronous tumours, the most frequent sites (excluding skin) were prostate (71), breast (51), colon (48) lung (44), and bladder (36) (table IV).

The multivariate analysis shows that overall, patients with NEN had a slight, not significant excess risk of having a second tumour (SIR 1.06, 95\% CI 0.98-1.15).

\section{DISCUSSION}

The epidemiology of NEN in Italy has been described in a fragmentary way in studies on rare diseases (15) or as part of broader European studies $(16,17)$. In our study, the incidence of NENs in the last available year shows a rate of $5.46 / 100,000 /$ year (95\% Cl 4.90-6.06), slightly higher than that reported by Trama(15) in the period 2000-2010: rate 4.15 (95\% Cl 4.06-4.23). The trends of NENs in Italy have shown a rapid increase, from 1 to over 5 per 100,000 , similar to that reported by Yao in the US, where incidence increased from 1.09 in 1973 to 


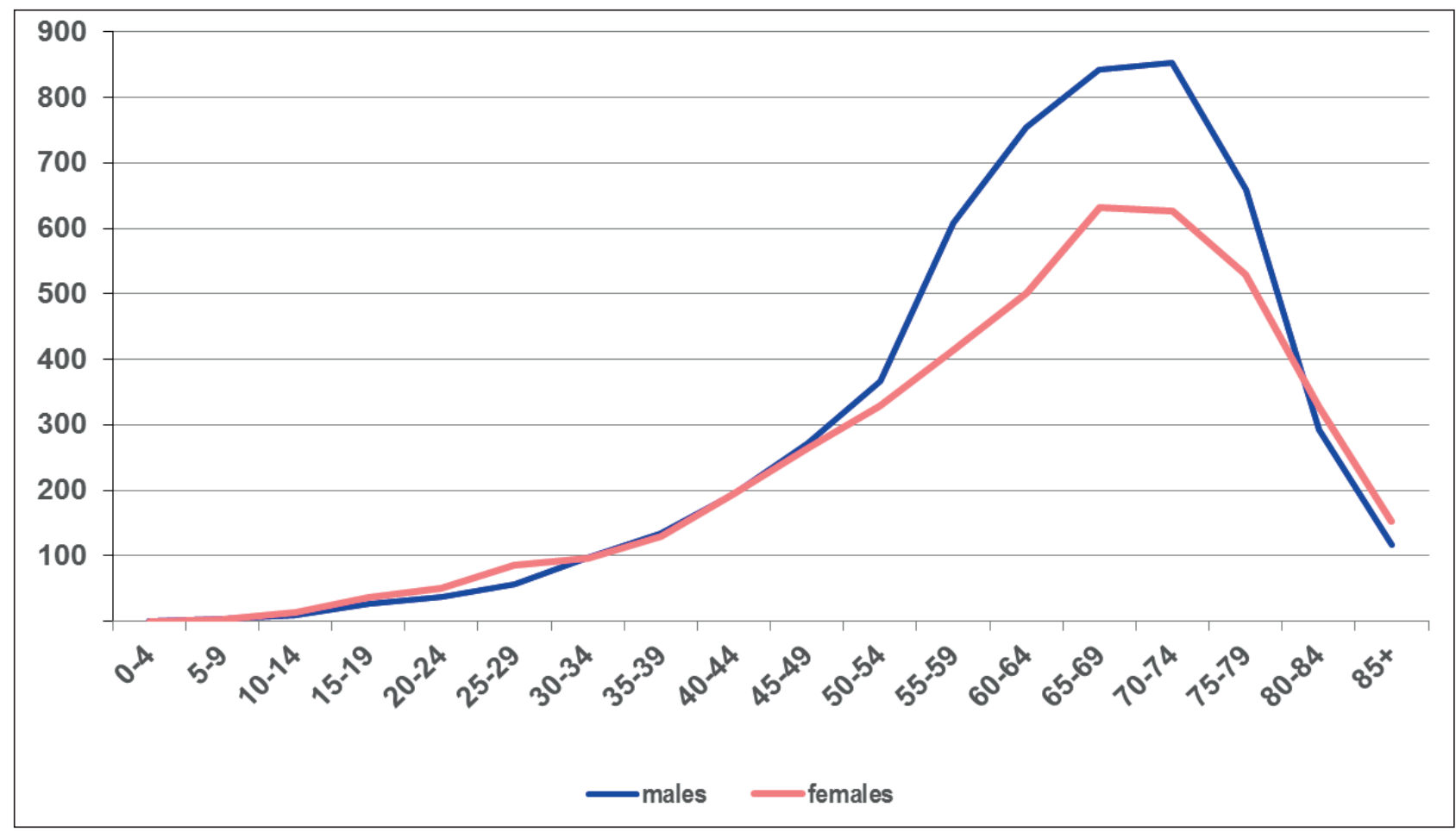

Figure 3. Specific incidence rates by age and sex per 1,000,000 persone/years. Years 1976-2012.

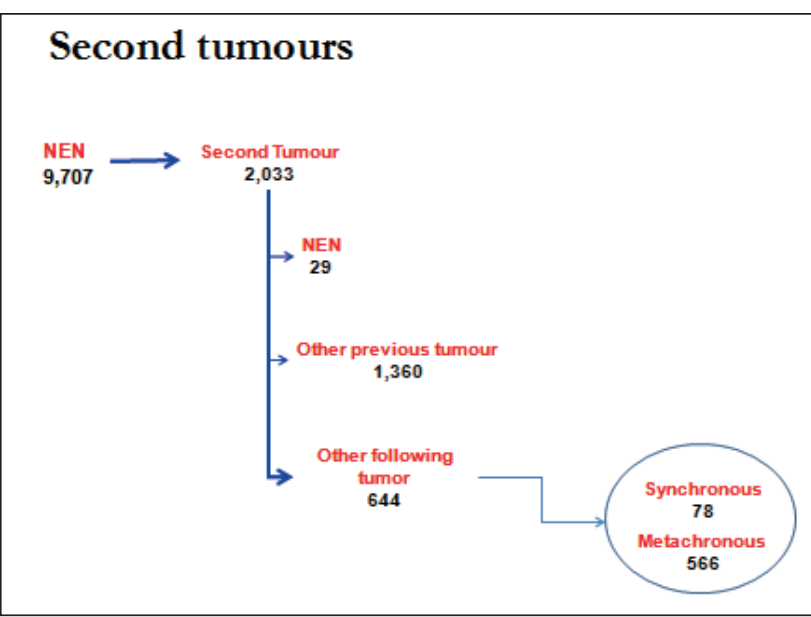

Figure 4. Second tumours in patients with NENs. Years 1976-2012.

\subsection{5/100.000 in 2004 (3), and in Northern Europe,} where incidence increased from 2.35 per 100,000 in the period 1993-1997 to 4.6 per 100,0000 in 2000-2004 (7). We cannot rule out that the advent of new diagnostic techniques, from CT to MR, from Octreoscan to Ga68 DOTA PET, from EUS to enteroclysis $\mathrm{CT}$ and video capsule, has greatly influenced the number of new diagnoses and consequently the incidence and time of survival. Another Italian study also reports this issue: cases diagnosed in the earlier period could be affected by a greater obsolete histological classification, while in more recent years, more sensitive classi-

\begin{tabular}{|l|l|}
\hline NENS & $\begin{array}{c}\text { ICD-0-3 } \\
\text { CODES }\end{array}$ \\
\hline Islet cell carcinoma & $8150 / 3$ \\
\hline Insulinoma & $8151 / 3$ \\
\hline Glucagonoma & $8152 / 3$ \\
\hline Gastrinoma & $8153 / 3$ \\
\hline Mixed islet-cell/exocrine adenocarcinoma & $8154 / 3$ \\
\hline Vipoma & $8155 / 3$ \\
\hline Somatostatinoma & $8156 / 3$ \\
\hline Enteroglucagonoma & $8157 / 3$ \\
\hline Carcinoid & $8240 / 3$ \\
\hline Enterochromaffin cell carcinoid & $8241 / 3$ \\
\hline Enterochromaffin-like cell tumours & $8242 / 3$ \\
\hline Goblet cell carcinoid & $8243 / 3$ \\
\hline Composite carcinoid & $8244 / 3$ \\
\hline Adenocarcinoid & $8245 / 3$ \\
\hline Neuroendocrine carcinoma & $8246 / 3$ \\
\hline Atypical carcinoid & $8249 / 3$ \\
\hline
\end{tabular}

Table I. List of morphological codes included in this study.

fications and imaging could guarantee greater diagnostic accuracy (18).

Lung and small intestine were the most common sites in Italy in both sexes, like in the US and Northern Europe $(3,7)$; however, we found a higher proportion of pancreatic tumours compared with these studies. It should be noted that all pancreatic cancers have shown a rapid increase in the Italian population in the last 10 years (19). In this study, instead, we observed fewer rectal cancers $(5 \%$ in 


\begin{tabular}{|c|c|c|c|c|c|c|c|}
\hline \multirow[b]{2}{*}{ ICDO3 } & \multirow[b]{2}{*}{ SITE } & \multicolumn{2}{|l|}{ MALES } & \multicolumn{2}{|l|}{ FEMALES } & \multicolumn{2}{|l|}{ TOTAL } \\
\hline & & N. & $\%$ & N. & $\%$ & N. & $\%$ \\
\hline $\mathrm{COO}-\mathrm{C} 14$ & Oral cavity and pharynx & 11 & 0.2 & 11 & 0.3 & 22 & 0.2 \\
\hline C15 & Esophagus & 14 & 0.3 & 8 & 0.2 & 22 & 0.2 \\
\hline C16 & Stomach & 434 & 8.2 & 420 & 9.6 & 854 & 8.8 \\
\hline C17 & Small intestine & 852 & 16.0 & 561 & 12.8 & 1,413 & 14.6 \\
\hline C18 & Colon (including appendix) & 507 & 9.5 & 532 & 12.1 & 1,039 & 10.7 \\
\hline C19 & Rectosigmoid junction & 36 & 0.7 & 18 & 0.4 & 54 & 0.6 \\
\hline $\mathrm{C} 20$ & Rectum & 248 & 4.7 & 210 & 4.8 & 458 & 4.7 \\
\hline C21 & Anus and anal canal & 14 & 0.3 & 17 & 0.4 & 31 & 0.3 \\
\hline C22 & Liver-intrahepatic bile ducts & 54 & 1.0 & 37 & 0.8 & 91 & 0.9 \\
\hline C23-24 & Gallbladder-extrahepatic ducts & 57 & 1.1 & 59 & 1.3 & 116 & 1.2 \\
\hline C25 & Pancreas & 541 & 10.2 & 506 & 11.5 & 1,047 & 10.8 \\
\hline C26 & Other digestive organs & 32 & 0.6 & 31 & 0.7 & 63 & 0.6 \\
\hline C30-31 & Nasal cavity & 21 & 0.4 & $<3$ & 0.0 & 23 & 0.2 \\
\hline C32-34 & Lung & 1,902 & 35.8 & 1,301 & 29.6 & 3,203 & 33.0 \\
\hline C37-39 & Other intrathoracic organs (also thymus) & 55 & 1.0 & 24 & 0.6 & 79 & 0.8 \\
\hline C40-41 & Bone & 0 & 0.0 & $<3$ & 0.0 & $<3$ & 0.0 \\
\hline C44 & Skin & 5 & 0.1 & 10 & 0.2 & 15 & 0.1 \\
\hline C47. C49 & Soft tissue & $<3$ & 0.0 & 3 & 0.1 & 5 & 0.0 \\
\hline C48 & Retroperitoneum & 15 & 0.3 & 8 & 0.2 & 23 & 0.2 \\
\hline C50 & Breast & 0 & 0.0 & 140 & 3.2 & 140 & 1.4 \\
\hline C51-C58 & Female genital organs & & 0.0 & 125 & 2.9 & 125 & 1.3 \\
\hline $\mathrm{C} 60-\mathrm{C} 63$ & Male genital organs & 29 & 0.6 & & 0.0 & 29 & 0.3 \\
\hline C64-C68 & Urinary organs & 73 & 1.4 & 19 & 0.4 & 92 & 0.9 \\
\hline C69 & Eye & $<3$ & 0.0 & & 0.0 & $<3$ & 0.0 \\
\hline C70-C72 & Brain & $<3$ & 0.0 & 3 & 0.1 & 5 & 0.1 \\
\hline C74-C75 & Adrenal and other endocrine glands & 19 & 0.4 & 19 & 0.4 & 38 & 0.4 \\
\hline C76-77-C80 & Unknown site & 394 & 7.4 & 324 & 7.4 & 718 & 7.4 \\
\hline TOTAL & & 5,318 & 100 & 4,389 & 100 & 9,707 & 100 \\
\hline
\end{tabular}

Table II. Frequency of most common NENs, by site and sex. Years 1976-2012.

Italy, over $12 \%$ in the US, $7 \%$ in Northern Europe). It cannot be excluded that the Mediterranean diet, which is protective in terms of aggressiveness and stage of the disease, can also influence this tumour's incidence (20).

The incidence by age confirms an increase in the adult-elderly population but a decrease in adults over age 75 years, and that males have a higher risk than do females (3). Five-year relative survival was $66.5 \%$ in females and 53.9 in males, similar to that seen in SEER (55\%), NCR (50\%), and Italian data (63\%) (21), though referring to different periods.

The median survival in our study was lower than that reported by Faggiano and colleagues in a large Italian case series, but they included a different mix of cancers due to using a different classification of NENs (18). The different survival, compared to other studies, could be linked to the fact that ours is a population-based study and therefore the heterogeneity of NENs and probably the lack of inclusion in the registry data of the subtypes associated with less biological aggressiveness (which are generally followed up in the outpatient setting and so are not registered in the Hospital Discharge Records system or in the pathology databases) may explain this lower survival. Furthermore, as our data refer to an earlier period (1976-2010), the impact of newly available effective treatments, even for metastatic cancer, has not yet been observed (22). In our study, NEN patients had a slight, not signif- 


\begin{tabular}{|c|c|c|c|c|c|c|c|c|c|c|c|c|}
\hline \multirow{3}{*}{$\begin{array}{l}\text { YEAR } \\
1976 \\
\end{array}$} & \multicolumn{4}{|c|}{ MALES } & \multicolumn{4}{|c|}{ FEMALES } & \multicolumn{4}{|c|}{ ALL CASES } \\
\hline & \multirow{2}{*}{$\begin{array}{l}\text { RATE } \\
0.92\end{array}$} & \multirow{2}{*}{$\begin{array}{l}\text { STANDARD } \\
\text { ERROR } \\
0.53\end{array}$} & \multicolumn{2}{|c|}{$95 \% \mathrm{Cl}$} & \multirow{2}{*}{\begin{tabular}{|l|} 
RATE \\
1.08 \\
\end{tabular}} & \multirow{2}{*}{$\begin{array}{l}\text { STANDARD } \\
\text { ERROR }\end{array}$} & \multicolumn{2}{|c|}{$95 \% \mathrm{Cl}$} & \multirow{2}{*}{$\begin{array}{l}\text { RATE } \\
1.02\end{array}$} & \multirow{2}{*}{$\begin{array}{l}\text { STANDARD } \\
\text { ERROR } \\
0.43\end{array}$} & \multicolumn{2}{|c|}{$95 \% \mathrm{Cl}$} \\
\hline & & & 0.19 & 3.29 & & & 0.22 & 3.08 & & & 0.36 & 2.27 \\
\hline 1977 & 0.43 & 0.43 & 0.01 & 2.75 & 0.27 & 0.27 & 0.01 & 1.61 & 0.35 & 0.25 & 0.04 & 1.30 \\
\hline 1978 & 0.38 & 0.27 & 0.04 & 1.65 & 0.31 & 0.23 & 0.04 & 1.20 & 0.34 & 0.17 & 0.09 & 0.93 \\
\hline 1979 & 0.72 & 0.42 & 0.15 & 2.22 & 0.16 & 0.16 & 0.00 & 0.94 & 0.39 & 0.20 & 0.11 & 1.01 \\
\hline 1980 & 1.34 & 0.62 & 0.42 & 3.18 & 0.85 & 0.38 & 0.27 & 1.99 & 1.06 & 0.33 & 0.52 & 1.93 \\
\hline 1981 & 0.70 & 0.36 & 0.18 & 1.89 & 0.59 & 0.30 & 0.16 & 1.51 & 0.65 & 0.23 & 0.28 & 1.29 \\
\hline 1982 & 0.46 & 0.27 & 0.09 & 1.47 & 0.84 & 0.34 & 0.30 & 1.83 & 0.64 & 0.21 & 0.29 & 1.23 \\
\hline 1983 & 0.56 & 0.29 & 0.15 & 1.59 & 1.00 & 0.38 & 0.40 & 2.06 & 0.80 & 0.24 & 0.40 & 1.44 \\
\hline 1984 & 1.23 & 0.70 & 0.27 & 3.15 & 0.69 & 0.31 & 0.22 & 1.62 & 0.85 & 0.29 & 0.38 & 1.60 \\
\hline 1985 & 1.05 & 0.31 & 0.54 & 1.87 & 0.66 & 0.23 & 0.28 & 1.29 & 0.83 & 0.19 & 0.51 & 1.29 \\
\hline 1986 & 1.00 & 0.25 & 0.58 & 1.62 & 0.92 & 0.21 & 0.55 & 1.44 & 0.96 & 0.16 & 0.67 & 1.33 \\
\hline 1987 & 1.32 & 0.26 & 0.86 & 1.93 & 1.01 & 0.20 & 0.65 & 1.49 & 1.16 & 0.16 & 0.87 & 1.53 \\
\hline 1988 & 1.23 & 0.22 & 0.84 & 1.75 & 1.30 & 0.21 & 0.93 & 1.77 & 1.27 & 0.15 & 1.00 & 1.61 \\
\hline 1989 & 1.95 & 0.29 & 1.41 & 2.61 & 1.14 & 0.19 & 0.80 & 1.58 & 1.49 & 0.16 & 1.18 & 1.84 \\
\hline 1990 & 1.62 & 0.24 & 1.19 & 2.16 & 1.11 & 0.18 & 0.78 & 1.51 & 1.33 & 0.14 & 1.06 & 1.64 \\
\hline 1991 & 1.92 & 0.25 & 1.45 & 2.48 & 1.37 & 0.19 & 1.03 & 1.79 & 1.61 & 0.15 & 1.33 & 1.94 \\
\hline 1992 & 1.52 & 0.21 & 1.14 & 1.99 & 1.69 & 0.20 & 1.31 & 2.13 & 1.61 & 0.15 & 1.34 & 1.92 \\
\hline 1993 & 1.48 & 0.20 & 1.12 & 1.92 & 1.58 & 0.19 & 1.23 & 1.99 & 1.55 & 0.14 & 1.29 & 1.84 \\
\hline 1994 & 2.30 & 0.24 & 1.85 & 2.82 & 1.45 & 0.17 & 1.14 & 1.82 & 1.83 & 0.14 & 1.56 & 2.12 \\
\hline 1995 & 2.42 & 0.23 & 1.99 & 2.92 & 1.71 & 0.17 & 1.40 & 2.07 & 1.99 & 0.13 & 1.74 & 2.27 \\
\hline 1996 & 2.18 & 0.19 & 1.81 & 2.59 & 1.41 & 0.14 & 1.15 & 1.71 & 1.74 & 0.12 & 1.53 & 1.98 \\
\hline 1997 & 2.66 & 0.22 & 2.25 & 3.11 & 1.94 & 0.16 & 1.63 & 2.28 & 2.24 & 0.13 & 1.99 & 2.51 \\
\hline 1998 & 2.64 & 0.21 & 2.25 & 3.07 & 1.87 & 0.16 & 1.57 & 2.20 & 2.21 & 0.13 & 1.97 & 2.48 \\
\hline 1999 & 3.14 & 0.21 & 2.74 & 3.57 & 1.72 & 0.14 & 1.46 & 2.01 & 2.32 & 0.12 & 2.10 & 2.56 \\
\hline 2000 & 2.86 & 0.20 & 2.49 & 3.27 & 2.15 & 0.15 & 1.86 & 2.47 & 2.46 & 0.12 & 2.23 & 2.70 \\
\hline 2001 & 3.53 & 0.21 & 3.12 & 3.98 & 2.48 & 0.16 & 2.17 & 2.83 & 2.95 & 0.13 & 2.70 & 3.22 \\
\hline 2002 & 3.74 & 0.22 & 3.32 & 4.19 & 2.25 & 0.15 & 1.95 & 2.57 & 2.89 & 0.13 & 2.65 & 3.16 \\
\hline 2003 & 3.55 & 0.19 & 3.19 & 3.95 & 2.55 & 0.15 & 2.28 & 2.85 & 3.00 & 0.12 & 2.77 & 3.23 \\
\hline 2004 & 3.89 & 0.20 & 3.51 & 4.30 & 2.54 & 0.14 & 2.27 & 2.84 & 3.11 & 0.12 & 2.88 & 3.35 \\
\hline 2005 & 4.06 & 0.20 & 3.68 & 4.47 & 2.91 & 0.15 & 2.62 & 3.23 & 3.41 & 0.12 & 3.18 & 3.66 \\
\hline 2006 & 4.43 & 0.21 & 4.02 & 4.86 & 2.70 & 0.15 & 2.42 & 3.00 & 3.43 & 0.12 & 3.19 & 3.68 \\
\hline 2007 & 5.15 & 0.22 & 4.74 & 5.59 & 3.26 & 0.16 & 2.96 & 3.58 & 4.08 & 0.13 & 3.84 & 4.34 \\
\hline 2008 & 4.27 & 0.21 & 3.87 & 4.70 & 2.98 & 0.16 & 2.67 & 3.31 & 3.56 & 0.13 & 3.32 & 3.83 \\
\hline 2009 & 5.52 & 0.27 & 5.00 & 6.08 & 3.65 & 0.20 & 3.27 & 4.07 & 4.48 & 0.16 & 4.16 & 4.81 \\
\hline 2010 & 6.51 & 0.48 & 5.61 & 7.51 & 4.60 & 0.36 & 3.91 & 5.37 & 5.46 & 0.29 & 4.90 & 6.06 \\
\hline
\end{tabular}

Table III. EU Standardized incidence of NEN by year and sex. Years 1976-2010.

icant excess risk of having a second tumour: the standardized incidence ratio was $1.06(95 \% \mathrm{Cl}$ 0.98-1.15). Also, the probability of having a second tumour (all tumours) in Italy was $1.08(95 \% \mathrm{Cl}$ 1.08-1.09) for men and 1.12 (95\% Cl 1.11-1.13) for women (23). The occurrence of a second cancer was about $21 \%$. In other studies, second cancers were reported to occur in $10-20 \%$ of NEN patients, but this figure was influenced by the length of follow-up after NEN occurrence (24-27).

In Tsai's study, an increased risk of developing second cancers was observed, particularly for urinary tract cancers (28). Among the 1,350 NEN patients diagnosed between 1996 and 2006 in Taiwan, 3.6\% de- 


\begin{tabular}{|l|c|c|}
\hline & \multicolumn{2}{|c|}{ SYNCHRONOUS TUMORS } \\
\hline SITE & $\mathrm{n}$. & $\%$ \\
\hline LUNG & 15 & 19.2 \\
\hline COLON & 11 & 14.1 \\
\hline PROSTATE & 6 & 7.7 \\
\hline KIDNEY & 6 & 7.7 \\
\hline THYROID & 6 & 7.7 \\
\hline OTHER SITES & 34 & 43.6 \\
\hline TOTAL & 78 & 100.0 \\
\hline & METACHRONOUS TUMORS \\
\hline SKIN & 100 & 17.7 \\
\hline PROSTATE & 71 & 12.5 \\
\hline BREAST & 51 & 9.0 \\
\hline COLON & 48 & 8.5 \\
\hline LUNG & 44 & 7.8 \\
\hline BLADDER & 36 & 6.4 \\
\hline OTHER SITES & 216 & 38.2 \\
\hline TOTAL & 566 & 100.0 \\
\hline
\end{tabular}

Table IV. Second tumours (synchronous and metachronous) in patients with NEN diagnosis.

( $*$ In italics are the cancer registries that have merged in recent years).

veloped metachronous second cancers; in our study, the percentage was higher (6.6\%). The increased risk of a second cancer following NEN could be due to several factors, including genetic, lifestyle, and/or treatment-related factors (29). Patients with familial NENs may also be more susceptible to developing cancer other than NEN (27). Also a small Irish study reported 14 second tumours among 46 patients with NENs: although the numbers are small, the follow-up of these patients needs to be optimized (30). Unfortunately, Italian cancer registries do not routinely report the NEN classification based on grade of differentiation, which is collected only for high-resolution studies. Furthermore, including data from the early 1970s means that only morphology and topography codes can be considered. Therefore, a more detailed comparisons with the RITA or the RARECARE studies cannot be conducted $(15,16)$. Another limitation of our study is that we could not distinguish between cases occurring in patients with MEN-1 and in those with MEN-2 syndromes and other genetic endocrine syndromes (VHL, NF, SHD, and others). AIRTUM data based on ICD codes are not up to date with regard to the numerous subtypes of neuroendocrine tumours; functional NENs are underreported in many cancer registries and distinguishing between benign and malignant behaviour may thus be difficult. Analysing other comorbidities, such as obesity, hypertension, and diabetes, would also have been of interest, but this information is unfortunately not currently available in cancer registry databases.

The study includes data from 38 cancer registries, which corresponds to around 30 million Italians, and spans a period of almost 40 years of registration, but geographic and temporal distributions are not homogenous. This heterogeneity among the registers in different periods could have affected our incidence trend estimate and did not allow us to study the trend of survival. Furthermore, there may be an underestimation linked to the fact that many tumours with neuroendocrine features might be under-reported in mortality certificates, i.e., reporting "colon cancer" or "pancreatic adenocarcinoma" instead of their NENs counterparts.

\section{CONCLUSIONS}

In our study, the incidence of NENs in Italy was 5 per 100,000 . Although traditionally thought to be rare, incidence has increased by nearly sevenfold since 1976. Five-year relative survival is $66.5 \%$ in females and 53.9 in males without any improvement over time.

The occurrence of a second cancer was about $21 \%$, with a slight, although not significant excess of risk. The availability of population-based data and second cancers associated with NENs could support clinicians in making the most appropriate choice for the management of patients with NENs.

\section{ACKNOWLEDGMENTS}

The authors thank the participating cancer registries for collecting and preparing the data as part of their essential role in cancer control.

Indeed, thanks to the AIRTUM Working Group (Rosso S. Piemonte Cancer Registry (CR); Pisani S. Insubria CR; Tagliabue G. Varese CR; FaNENti AC. ATS Montagna CR; Cavalieri d'Oro L. Brianza CR; Russo AG. ATS Milano CR; Ricci P. Valpadana CR; Magoni M. Brescia CR; Sampietro G. Bergamo CR; Serraino D. Friuli Venezia Giulia CR; Piffer S. Trento CR; Mazzoleni G. Alto Adige CR; Rugge M. VeNENo CR; Filiberti RA. Liguria CR; Chiaranda G. Piacenza CR; Mi- 
chiara M. Parma CR; Mangone L. Reggio Emilia CR; Carrozzi G. Modena CR; Ferretti S. Ferrara CR; Falcini F. Romagna CR; Caldarella A. Toscana CR; Vitarelli S. Macerata CR; Stracci F. Umbria CR; Iacovacci S. Latina CR; Ortolani R. Napoli Centro CR; D’Orsi G. Napoli Nord CR; Fusco M. Napoli Sud CR; Scala U. Salerno CR; Coviello E. Barletta-Andria-Trani CR; Quarta F. Lecce CR; Minerba S. Taranto CR; Sutera Sardo A. Catanzaro CR; Sciacca S. Catania-Messina-Enna CR; Vitale F. Palermo CR; Tumino R. Ragusa-Caltanissetta CR; Madeddu A. Siracusa CR; Candela G. Trapani-Agrigento $C R$; Cesaraccio R. Sassari CR).

\section{ETHICS}

\section{Fundings}

There were no institutional or private fundings for this article.

\section{Conflict of interests}

The authors have declared no conflict of interests.

\section{Availability of data and material}

All the data supporting the findings of this study are available within the article and can be shared just before a reasonable request to the corresponding author.

\section{Authors' contribution}

LM: conceptualization, investigation, writing-original draft, visualization, supervision; CS: methodology; IB: writing - review \& editing, supervision; PM: methodology; GC: conceptualization, supervision; PGR: conceptualization, writing-original draft, supervision. All authors have read and agreed to the published version of the manuscript.

\section{Ethical approval}

N/A 


\section{REFERENCES}

1. Modlin IM, Lye KD, Kidd M. A 5-decade analysis of 13.715 carcinoid tumors. Cancer 2003;97:934-59.

2. Alexandraki K, Tsoli M, Kyriakopoulos G, et al. Current concepts in the diagnosis and management of neuroendocrine neoplasms of unknown primary origin. Minerva Endocrinol 2019;44(4):378-86

3. Yao JC, Hassan M, Phan A, et al. One hundred years after "carcinoid": epidemiology of and prognostic factors for neuroendocrine tumors in 35.825 cases in the United States. J Clin Oncol 2008;26(18):3063-72.

4. Godwin JD. Carcinoid tumors. An analysis of 2.837 cases. Cancer 1975;36:560-69.

5. Lepage C, Rachet B, Coleman MP. Survival from malignant digestive endocrine tumors in England and wales: A population-based study. Gastroenterology 2007;132:899-904.

6. Yao JC, Eisner MP, Leary C. et al. Population based study of islet cell carcinoma. Ann Surg Oncol 2007;14:3492-500.

7. Hauso O, Gustafsson BI, Kidd M, et al. Neuroendocrine tumor epidemiology: contrasting Norway and North America. Cancer 2008;113(10):2655-64.

8. Fritz AG. International Classification of Diseases for Oncology: ICD-O (ed 3). Geneva, Switzerland. World Health Organization 2000.

9. Rindi G, Kloppel G, Alhman H, et al. TNM staging of foregut (neuro)endocrine tumors: a consensus proposal including a grading system. Virchow Arch 2006;449(4): 395-401.

10. Rindi G, Kloppel G, Couvelard A, et al. NM staging of midgut and hindgut (neuro)endocrine tumors: a consensus proposal including a grading system. Virchow Arch 2007;451(4):757-62.

11. Rindi G, Klimstra DS, Abedi-Ardekani B, et al. A common classification framework for neuroendocrine neoplasms: an International Agency for Research on Cancer (IARC) and World Health Organitation (WHO) expert consensus proposal. Mod Pathol 2018;31(12):1770-86.

12. Digestive System Tumours WHO Classification of Tumours, $5^{\text {th }}$ Edition, Volume 1. WHO Classification of Tumours Editorial Board. ISBN-13 (Print Book). 978-92-832-4499-8.

13. Female Genital Tumours WHO Classification of Tumours, $5^{\text {th }}$ Edition, Volume 4 . WHO Clas- sification of Tumours Editorial Board. ISBN-13 (Print Book). 978-92-832-4504-9.

14. Grunkemeier GL, Anderson RP, Starr A. Actuarial and actual analysis of surgical results: empirical validation. Ann Thorac Surg 2001;71:1885-7.

15. Trama A, Mallone $S$, Ferretti $S$, et al. The burden of rare cancers in Italy: the surveillance of rare cancers in Italy (RITA) project. Tumori 2012;98(5):550-8.

16. Gatta G, Capocaccia R, Botta L, et al. Burden and centralised treatment in Europe of rare tumours: results of RARECAREnet-a population-based study. Lancet Oncol. 2017;18(8):1022-39.

17. Van der Zwan JM, Trama A, Otter R, et al. Rare neuroendocrine tumours: results of the surveillance of rare cancers in Europe project. Eur J Cancer 2013;49(11):2565-78.

18. Faggiano A, Ferolla P, Grimaldi F, Campana $D$, Manzoni M, Davì MV, et al. Natural history of gastro-entero-pancreatic and thoracic neuroendocrine tumors. Data from a large prospective and retrospective Italian epidemiological study: the NET management study. J Endocrinol Invest 2012;35(9):817-23.

19. I numeri del cancro in Italia 2019. Aiom-Airtum-Passi-Passi D'argento-Siapec-lap. Intermedia editore, Settembre 2019.

20. Barrea L, Altieri B, Muscogiuri G, et al. Impact of Nutritional Status on Gastroenteropancreatic Neuroendocrine Tumors (GEP-NET) Aggressiveness. Nutrients. 2018;10(12).pii:E1854.Doi: 10.3390/nu10121854.

21. AIRTUM Working Group, Busco S, Buzzoni C, et al. Italian cancer figures-Report 2015: The burden of rare cancers in Italy. Epidemiol Prev 2016;40(1 Suppl 2):1-120.

22. Lesén $E$, Granfeldt $D$, Berthon A, Dinet J, Houchard A, Myrenfors P, et al. Treatment Patterns and Survival among Patients with Metastatic Gastroenteropancreatic Neuroendocrine Tumours in Sweden-a Population-based Register-linkage and Medical Chart Review Study. J Cancer 2019;10(27):6876-87.

23. Buzzoni C, Crocetti E, Bella F, et al. I tumori in Italia- Rapporto 2013, Tumori multipli. Epidemiol Prev 37 (4-5) Suppl 1:1-152.

24. Moertel CG, Sauer WG, Dockerty MB, Baggenstoss $\mathrm{AH}$. Life history of the carcinoid tumor of the small intestine. Cancer 1961;14:901-2. 
25. Prommegger $R$, Ensinger $C$, Steiner $P$, et al. Neuroendocrine tumors and second primary malignancy-a relationship with clinical impact? Anticancer Res 2004;24:1049-51.

26. Perez EA, Koniaris LG, Snell SE, et al. 7201 carcinoids: increasing incidence overall and disproportionate mortality in the elderly. World J Surg 2007;31:1022-30.

27. Krausch M, Raffel A, Anlauf M, et al. Secondary malignancy in patients with sporadic neuroendocrine neoplasia. Endocrine 2013;44:510-6.

28. Tsai HJ, Wu CC, Tsai CH, Lin FS, Chen LT, Chang J. Second Cancers in Patients with Neuroendo- crine Tumors. PLoS One 2013;8(12):e86414.

29. Travis LB, Demark Wahnefried W, Allan JM, Wood ME, Ng AK. Aetiology. geNENics and prevention of secondary neoplasms in adult cancer survivors. Nat Rev Clin Oncol 2013;10:289-301.

30. Agasarova A, Harnett C, Mulligan N, Shakeel Majeed M, Caimo A, Gianluca Tamagno G. Int J Endocrinol Management and Follow-up of Patients with a Bronchial Neuroendocrine Tumor in the Last Twenty Years in Ireland: Expected Inconsistencies and Unexpected Discoveries. Published online Aug 292018. 